\title{
Preparation and properties of heat-sealable polyimide films with comparable coefficient of thermal expansion and good adhesion to copper matrix
}

\author{
X. M. Zhang ${ }^{1}, X . X i a o^{2}, X . W u^{2}, J . G$. Liu $^{* 2}$ \\ ${ }^{1}$ School of Electrical Engineering, Beijing Jiaotong University, 100044 Beijing, China; \\ ${ }^{2}$ School of Materials Science and Technology, China University of Geosciences, 100083 Beijing, China
}

Received 29 May 2017; accepted in revised form 8 July 2017

\begin{abstract}
A series of thermoplastic polyimide (PI) films (PI-1 PI-5) with intrinsic heat sealability have been synthesized by the high-temperature polycondensation reaction of asymmetrical 2,3,3',4'-oxydiphthalic anhydride (aODPA) and various aromatic diamines in order to meet the demands of advanced flexible copper clad laminates (FCCL). The derived PI resins had good solubility in polar aprotic solvents, such as $N$-methyl-2-pyrrolidone (NMP) and $N, N$-dimethylacetamide (DMAc) at a solid content up to $20 \mathrm{wt} \%$. Flexible and tough films could be cast from the PI/NMP solution and the films exhibited tensile strength higher than $83 \mathrm{MPa}$. Among the developed PIs, those derived from aODPA and benzimidazole-containing diamines, including PI-4 from aODPA and 2-(4-aminophenyl)-5-aminobenzimidazole (4APBI) and PI-5 from aODPA and 2-(3aminophenyl)-5-aminobenzimidazole (3APBI) exhibited the highest thermal stability (glass transition temperatures, $T_{\mathrm{g}}>340^{\circ} \mathrm{C}$ ), lowest linear coefficients of thermal expansion $\left(\mathrm{CTE}<35 \cdot 10^{-6} 1 / \mathrm{K}\right)$, and superior adhesion to copper foil (peeling strength $>1.0 \mathrm{~N} / \mathrm{mm}$ ). Flexible copper clad laminate (FCCL) with no curling was successfully prepared from PI-4 and copper foil.
\end{abstract}

Keywords: tailor-made polymers, polyimide, heat sealability, flexible copper clad laminates, low CTE

\section{Introduction}

Wholly aromatic polyimide (PI) films have been successfully used in modern industry for half a century due to their excellent comprehensive properties both in ordinary and in extreme environments [1-5]. However, most of the commercially available PI films possess poor thermoplastic nature, which cannot be processed via common heat sealing procedures because they usually decompose before reaching a molten state at elevated temperatures. The strong interand intra-molecular interactions in the molecular chains for standard PI films make it nearly impossible to be processed by hot-adhesion bonding procedures. In practical applications, such as in fabrication of flexible copper clad laminates (FCCLs) for advanced microelectronic assembly [6-10], PI film substrates have to be adhered to metals or other matrixes by the aid of additional epoxy, acrylic, silicone, or fluoro-polymer adhesives [11-13]. This would inevitably cause undesirable thickness increase for the components or severe reliability issues in extreme conditions. Thus, various efforts have been performed increasing the thermal processability (or thermoplasticity) of aromatic PI films while maintaining their intrinsic thermal and mechanical properties.

It has been well established in the literature that the methodologies improving the thermoplasticity of aromatic PI films and maintaining their inherent thermal stability are inevitably contradictory. Thus, one can only achieve the balance among various desirable properties for practical FCCL applications, including good heat sealability, high glass transition temperatures 
$\left(T_{\mathrm{g}}\right)$, low coefficient of thermal expansion (CTE), good adhesion to copper matrix, and so on. For example, by introduction flexible ether linkages, an intrinsically heat sealable PI film with the trademark of Kapton ${ }^{\circledR}-\mathrm{KJ}\left(T_{\mathrm{g}}: 220^{\circ} \mathrm{C}\right.$; CTE: $\left.60 \cdot 10^{-6} 1 / \mathrm{K}\right)$ was developed by Dupont, USA [14]. The film is reported to be derived from aromatic dianhydrides and aromatic diamines with flexible molecular structures, such as 1,4-bis(4-aminophenoxy) benzene or 1,3-bis (4-aminophenoxy)benzene. Additionally, by introduction of asymmetrical molecular structures, a series of heat sealable PI films from 2,3,3', $4^{\prime}$-oxydiphthalic acid dianhydride (aODPA) and ether-containing diamines were developed by Yokota and coworkers [15]. The derived aODPA-PIs exhibited excellent thermoplasticity as well as high $T_{\mathrm{g}}$ values due to the steric effects of their asymmetrical structures. Although several classes of heat sealable PI films have been reported in the literature, further improvements for their performances, including decreasing their CTE values to be match with that of copper foil (CTE: $\left.17 \cdot 10^{-6} 1 / \mathrm{K}\right)[16,17]$ and increasing their adhesion to copper matrix (peeling strength $>1.0 \mathrm{~N} / \mathrm{mm}$ ) have been continuously performed so as to meet the severe demands of advanced FCCL fabrications.

In the current work, as one of our continuous efforts developing high performance thermoplastic PI films for FCCLs $[14,18]$, a series of PI films based on aODPA and aromatic diamines with different characteristics were designed, synthesized and characterized. The effects of the specific substituents on their heat sealability, dimensional stability at elevated temperatures, and adhering properties to copper foil were investigated in detail.

\section{Experimental}

\subsection{Materials}

2,3,3',4'-Oxydiphthalic anhydride (aODPA), 4,4'-oxydianiline (ODA), 2-(4-aminophenyl)-5-aminobenzimidazole (4APBI) and 2-(3-aminophenyl)-5-aminobenzimidazole (3APBI) were purchased from Changzhou Sunlight Pharmaceutical Co., Ltd., Jiangsu, China. The diamines were used as received and aODPA was dried in vacuo at $150^{\circ} \mathrm{C}$ for $12 \mathrm{~h}$ prior to use. para-Phenylenediamine (PDA) was obtained from Tokyo Chemical Industry, Japan and used directly. 2-Phenyl-4,4'-diaminodiphenylether (pODA) was synthesized according to ref [19] and recrystallized twice from absolute ethanol before use. $\mathrm{N}$-methyl-2pyrrolidone (NMP), N,N-dimethylacetamide (DMAc),
$\mathrm{N}, \mathrm{N}$-dimethylforamide (DMF) were distilled prior to use and stored under $4 \AA$ molecular sieve. The other commercially available reagents including $m$-cresol, tetrahydrofuran, chloroform (Beijing Yili Fine Chemicals Co. Ltd., China) and isoquinoline (Alfa Aesar, USA) were used as received. The rolled copper foil (thickness: $25 \mu \mathrm{m}$ ) without any surface treatment was purchased from Alfa Aesar, USA and used as received.

\subsection{Characterization}

Inherent viscosity was measured using an Ubbelohde viscometer with a $0.5 \mathrm{~g} / \mathrm{dL}$ NMP solution at $30^{\circ} \mathrm{C}$. Fourier-transform infrared (FT-IR) spectra were measured with a Bruker Tensor 27 FTIR spectrometer. Differential scanning calorimetry (DSC) was carried on a TA-Q 100 thermal analysis system at a heating rate of $10^{\circ} \mathrm{C} / \mathrm{min}$ in nitrogen. Thermogravimetric analysis (TGA) was performed on a TA-Q50 thermal analysis system at a heating rate of $20^{\circ} \mathrm{C} / \mathrm{min}$ in nitrogen. Thermomechanical analysis (TMA) was recorded on a TA-Q 400 thermal analysis system in nitrogen at a heating rate of $10^{\circ} \mathrm{C} / \mathrm{min}$. Dynamic mechanical analysis (DMA) was recorded on a TA-Q800 thermal analysis system at a heating rate of $5^{\circ} \mathrm{C} / \mathrm{min}$ and a frequency of $1 \mathrm{~Hz}$ in nitrogen. Mechanical properties were determined by tensile testing at a drawing rate of $2.0 \mathrm{~mm} / \mathrm{min}$ according to GB 13022-91.

Solubility was characterized as follows: $1.0 \mathrm{~g}$ of the PI resin was mixed into $9.0 \mathrm{~g}$ of the solvent tested (10 wt $\%$ solid content), which was stirred for $24 \mathrm{~h}$ at room temperature. The solubility was determined visually as three grades: completely soluble $(++)$, partially soluble $(+)$, and insoluble $(-)$, wherein complete soluble indicates a homogenous and clean state without phase separation, precipitation or gel formation, and insoluble indicates no change of the resin in the appearance.

Heat sealing for the PI films and copper $(\mathrm{Cu})$ coil were performed on a laboratory heat sealer (L0001, IDM Corp, Australia). Heat-sealing strengths of the PI-Cu composite films were obtained by $T$-type peeling test carried out on a tensile apparatus (Instron 3365 , USA) at a drawing rate of $300 \mathrm{~mm} / \mathrm{min}$. Five specimens were measured for each PI-Cu samples to give an average result.

\subsection{Polymer synthesis}

A series of PIs, including PI-1 (aODPA-PDA), PI-2 (aODPA-ODA), PI-3 (aODPA-pODA), PI-4 (aODPA- 
4APBI), and PI-5 (aODPA-3APBI) were synthesized via a one-step high temperature polycondensation procedure with $m$-cresol as the solvent and isoquinoline as the catalyst. As an example, the detailed synthesis procedure for PI-4 was as follows.

Into a $1000 \mathrm{~mL}$ three-necked, round-bottomed flask equipped with a mechanical stirrer, a Dean-Stark trap and a nitrogen inlet, $22.426 \mathrm{~g}(0.1 \mathrm{~mol})$ of $4 \mathrm{APBI}$ and $303 \mathrm{~g}$ of $m$-cresol were added. The mixture was stirred in an ice-water bath $\left(<15^{\circ} \mathrm{C}\right)$ under nitrogen blanket to obtain a homogeneous palebrown solution. Then, $31.021 \mathrm{~g}(0.1 \mathrm{~mol})$ of welldried aODPA was added into the reaction mixture in one batch, producing a mixture with a $15 \mathrm{wt} \%$ solid content. After stirring in nitrogen for $1 \mathrm{~h}$, a mixture of toluene $(36 \mathrm{~mL})$ and isoquinoline (catalytic amount) was then added. The reaction mixture was heated to $180^{\circ} \mathrm{C}$ and maintained for $5 \mathrm{~h}$. During the reaction, the toluene-water azeotrope was distilled out of the system and collected in the Dean-Stark trap. After cooling to room temperature, the viscous brown solution was carefully poured into an excess of ethanol to yield a yellow silky resin. The resin was collected and dried at $80^{\circ} \mathrm{C}$ in vacuo for $24 \mathrm{~h}$. Yield: $48.0 \mathrm{~g}(96 \%)$.

The well dried silky PI-4 resin was dissolved in newly-distilled DMAc at room temperature with a solid content of $20 \mathrm{wt} \%$. The obtained PI solution was filtered through a $0.45 \mu \mathrm{m}$ Teflon syringe filter to remove any undissolved impurities. Then, the solution was cast on a clean glass plate. The flexible and tough PI-4 film with a $25 \mu \mathrm{m}$ thicknesses was obtained by thermally baking the solution in flowing nitrogen according to the following heating procedure: $80^{\circ} \mathrm{C} / 2 \mathrm{~h}, \quad 120^{\circ} \mathrm{C} / 1 \mathrm{~h}, \quad 160^{\circ} \mathrm{C} / 1 \mathrm{~h}, 180^{\circ} \mathrm{C} / 1 \mathrm{~h}$, $240^{\circ} \mathrm{C} / 2 \mathrm{~h}$, and $250^{\circ} \mathrm{C} / 1 \mathrm{~h}$.

The other PI resin and films were prepared according to the similar procedures mentioned above.

\subsection{Fabrication of heat-sealing samples}

The adhesion of PI films and $\mathrm{Cu}$ foil was investigated by evaluating the heat sealing strength between the PI and $\mathrm{Cu}$ foil. Thus, heat-sealing samples were prepared first. Heat sealing of PI films was implemented with the hot-bar method on laboratory heat sealer, as presented in our previous work [18]. A pair of PI film and copper foil (thickness: $0.025 \mathrm{~mm}$ ) with the size of $90 \times 70 \times 0.025 \mathrm{~mm}$ were overlapped and plugged into the platen molds for $20 \mathrm{~mm}$ width at a set temperature depending on the glass transition temperatures $\left(T_{\mathrm{g}} \mathrm{s}\right)$ of the PI samples. Usually, the heat sealing temperatures for the samples was set to be around $20-50^{\circ} \mathrm{C}$ higher than those of their $T_{\mathrm{g}}$ values. The molds were kept for $1 \mathrm{~min}$ at $1.0 \mathrm{MPa}$. Then the hot-pressed sample was taken out and its two sides were reversed to repeat the process. To protect the films from the unexpected adhesion to the molds or each other caused by heat transfer, Kapton ${ }^{\circledR}$ film were covered outside and inserted into the two ribbons, respectively. After cooling down to room temperature, the heat-sealed sample was obtained and tailored for peeling test.

\section{Results and discussion}

\subsection{Polyimide synthesis}

As shown in Figure 1, five PIs, PI-1 PI-5 were prepared from aODPA and various aromatic diamines,

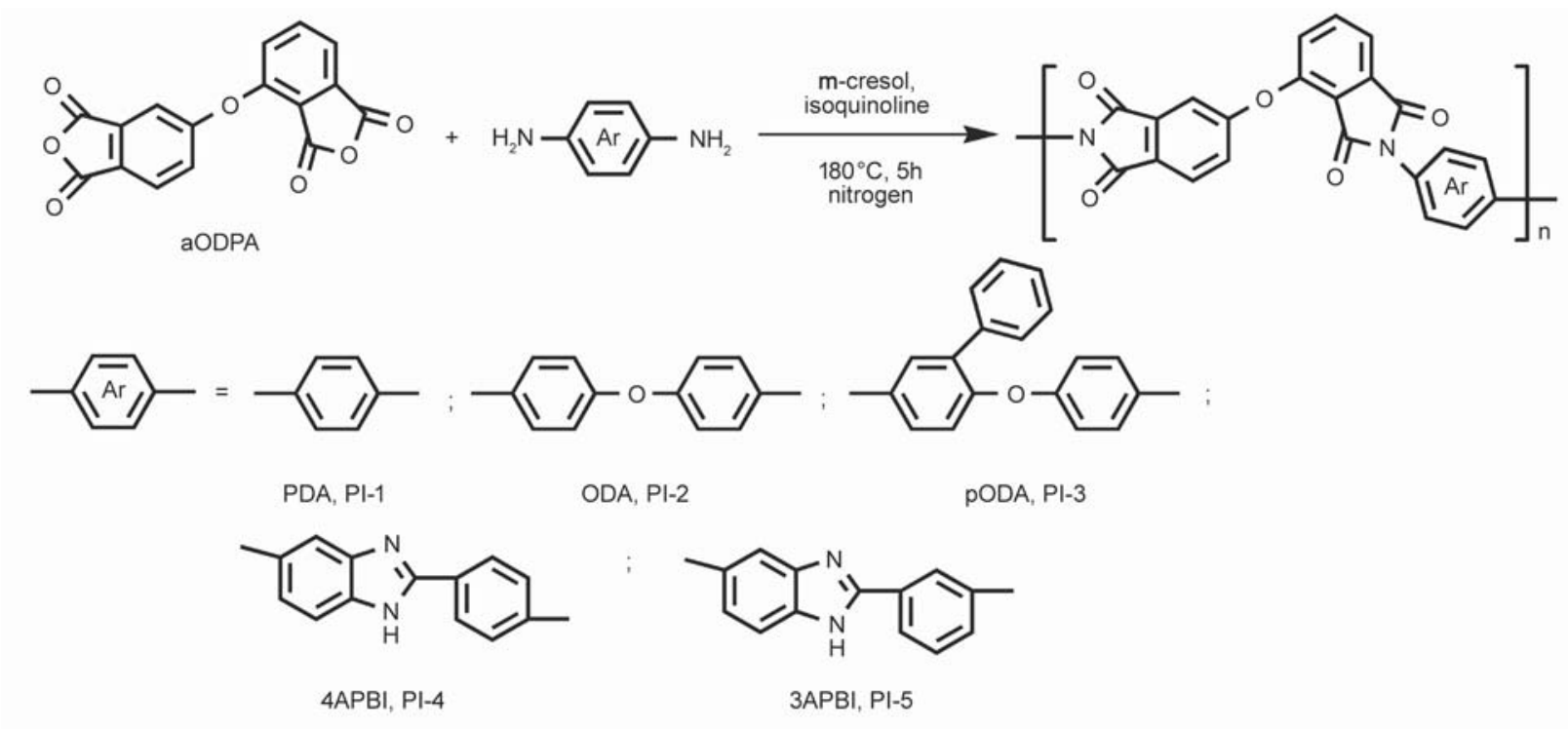

Figure 1. Synthesis of aODPA-PIs 
Table 1. Inherent viscosities and solubility of the PIs

\begin{tabular}{|c|c|c|c|c|c|c|c|c|}
\hline \multirow{2}{*}{ PI } & \multirow{2}{*}{$\begin{array}{l}{[\eta]_{\text {inh }}{ }^{a}} \\
{[\mathrm{dL} / \mathrm{g}]}\end{array}$} & \multicolumn{7}{|c|}{ Solubility $^{b}$} \\
\hline & & NMP & DMAc & DMF & $m$-cresol & $\mathrm{CHCl}_{3}$ & CPA & THF \\
\hline PI-1 & 0.97 & ++ & ++ & ++ & ++ & - & - & - \\
\hline PI-2 & 0.86 & ++ & ++ & ++ & ++ & - & - & - \\
\hline PI-3 & 0.82 & ++ & ++ & ++ & ++ & +- & +- & - \\
\hline PI-4 & 0.93 & ++ & ++ & ++ & ++ & - & - & - \\
\hline PI-5 & 0.76 & ++ & ++ & ++ & ++ & - & - & - \\
\hline
\end{tabular}

${ }^{\mathrm{a}}[\eta]_{\text {inh }}$ : inherent viscosity measured with PI resin in $N$-methyl-2-pyrrolidone (NMP) at a concentration of $0.5 \mathrm{~g} / \mathrm{dL}$ at $30^{\circ} \mathrm{C}$; $\mathrm{b}_{++}$: Completely soluble at room temperature; +: Partially soluble; - : Insoluble; NMP: $N$-methyl-2-pyrrolidone; DMAc: $N, N$-dimethylacetamide; DMF: $N, N$-dimethylformamide; CPA: cyclopentanone; THF: tetrahydrofuran

respectively via a one-step high-temperature polycondensation procedure. For the molecular design of the current PIs for potential applications in adhesiveless FCCLs, various functional groups were introduced into the PI structures. For instance, introduction of flexible ether linkages (-O- in aODPA) will endow the derived PIs with good thermoplasticity. The thermoplasticity could be further enhanced in $\mathrm{PI}-2$ and PI-3, containing both of -O- bonds in the dianhydride and diamine moieties. In PI-3, lateral phenyl substituent might further improve its processability. However, overloading of flexible groups might sacrifice the dimensional stability at elevated temperatures for the PI films (high CTE values) and decreasing their $T_{\mathrm{g}}$ values despite of the asymmetrical structures in aODPA unit. Therefore, PI-1, PI-4 and PI-5 containing either rigid para-substituted benzene or rigid benzimidazole moieties instead of flexible linkages in the diamine units were developed. These structural characteristics might bring good comprehensive properties for the PI films.

During the polycondensation reaction, all the polymerization proceeded homogeneously and no gel or precipitate formed. Finally, the PIs were obtained as continuous fibrous resins. The resins have inherent viscosities of $0.82-0.97 \mathrm{dL} / \mathrm{g}$ (Table 1 ), indicating moderate to high molecular weights of the polymers. The chemical structures of PI films were confirmed by FT-IR, as depicted in Figure 2. The similar spectra reveal the characteristic absorptions of the imide moieties at $1780 \mathrm{~cm}^{-1}\left(v_{\mathrm{as}, \mathrm{C}=\mathrm{O}}\right), 1720 \mathrm{~cm}^{-1}\left(\mathrm{v}_{\mathrm{s}, \mathrm{C}=\mathrm{O}}\right)$, and $1380 \mathrm{~cm}^{-1}\left(v_{\mathrm{C}-\mathrm{N}}\right)$. In addition, the deforming vibration peaks of imide $\mathrm{C}-\mathrm{N}$ around $721 \mathrm{~cm}^{-1}$ and the stretching vibration peak around $1250 \mathrm{~cm}^{-1}$ for $\mathrm{C}-\mathrm{O}-\mathrm{C}$ were also observed. All the information reveals the successful preparation of PIs.

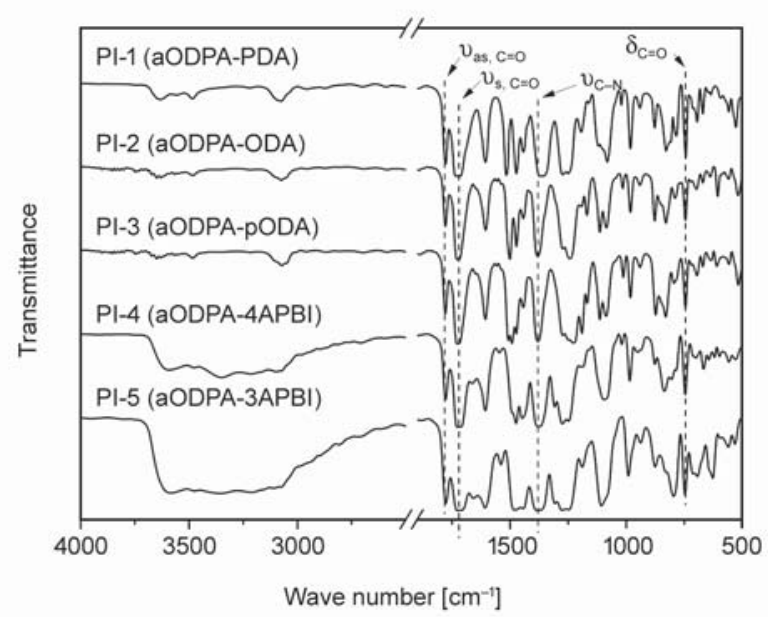

Figure 2. FT-IR spectra for aODPA-PI films

\subsection{Solubility and film quality}

The fully-dried PI resins were soluble in $N$-methyl2-pyrrolidone (NMP), N,N-dimethyl-formamide (DMF), and $N, N$-dimethylacetamide (DMAc) at a solid content of $10 \mathrm{wt} \%$ (Table 1). Flexible and tough PI films were cast from their resin solutions in NMP (10 wt \%). The PI films had tensile strength higher than $83 \mathrm{MPa}$, tensile modulus of 2.4-3.0 GPa, and elongations at break in the range of $6.5-11.4 \%$, as shown in Table 2.

Table 2. Film quality and mechanical properties of the PI films

\begin{tabular}{|c|c|c|c|c|}
\hline PI & $\begin{array}{c}\text { Film } \\
\text { quality }^{\mathbf{a}}\end{array}$ & $\begin{array}{c}\boldsymbol{T}_{\mathbf{S}}^{\mathbf{b}} \\
{[\mathbf{M P a}]}\end{array}$ & $\begin{array}{c}\boldsymbol{T}_{\mathbf{M}}^{\mathbf{b}} \\
{[\mathbf{G P a}]}\end{array}$ & $\begin{array}{c}\boldsymbol{E}_{\mathbf{b}} \mathbf{b} \\
{[\mathbf{\%}]}\end{array}$ \\
\hline PI-1 & F\&T & 113 & 2.4 & 7.8 \\
\hline PI-2 & F\&T & 112 & 2.4 & 9.2 \\
\hline PI-3 & F\&T & 120 & 2.7 & 6.5 \\
\hline PI-4 & F\&T & 108 & 3.0 & 7.7 \\
\hline PI-5 & F\&T & 83 & 2.8 & 11.4 \\
\hline
\end{tabular}

${ }^{\mathrm{a} F}$ : flexible

${ }^{\mathrm{b}} T_{\mathrm{S}}$ : tensile strength; $T_{\mathrm{M}}$ : tensile modulus; $E_{\mathrm{b}}$ : elongation at break

${ }^{\mathrm{c}} T$ : tough 


\subsection{Thermal properties}

The plots of thermogravimetric analysis (TGA) in nitrogen environment and differential scanning calorimetry (DSC) measurements for the PI films are shown in Figure 3 and Figure 4, respectively. The thermal data are tabulated in Table 3. As can be seen from Figure 3, all the PI films exhibited good thermal stability up to $500^{\circ} \mathrm{C}$. The $5 \%$ weight loss temperatures $\left(T_{5 \%}\right)$ are all higher than $520^{\circ} \mathrm{C}$. In addition, the PI films maintained more than $55 \%$ of their original weights at $750^{\circ} \mathrm{C}$. One of the main purposes for the current work is to increase the $T_{\mathrm{g}}$ values of the thermoplastic aODPA-PIs. In our previous work, a series of aODPA-PI films have been developed from aromatic diamines containing different ether contents [18]. Introduction of flexible ether linkages greatly deteriorated the glass transition temperature $\left(T_{\mathrm{g}}\right)$ values of the polymers. For example, PI from aODPA and ODA exhibited a $T_{\mathrm{g}}$ value of $284^{\circ} \mathrm{C}$; however, the one from aODPA and 4,4'-bis(4-aminophenoxy)diphenylether showed a $T_{\mathrm{g}}$ value of $229^{\circ} \mathrm{C}$. In the current work, for PI-2 (aODPA-ODA) and PI3 (aODPA-pODA), there is a considerable decrease

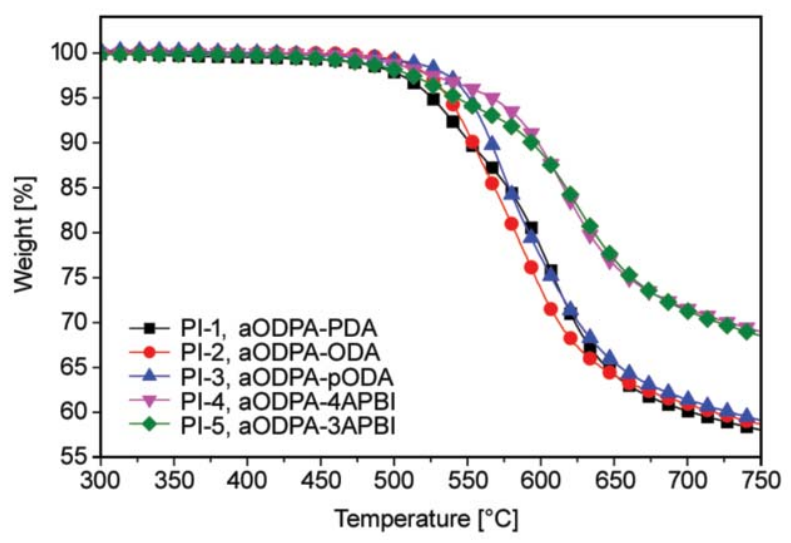

Figure 3. TGA curves for aODPA-PI films

Table 3. Thermal properties of aODPA-PI films ${ }^{\mathrm{a}}$

\begin{tabular}{|c|c|c|c|c|}
\hline PI & $\begin{array}{c}\boldsymbol{T}_{\mathbf{g}}, \mathbf{D S C} \\
{\left[{ }^{\circ} \mathbf{C}\right]}\end{array}$ & $\begin{array}{c}\boldsymbol{T}_{5 \%} \\
{\left[{ }^{\circ} \mathbf{C}\right]}\end{array}$ & $\begin{array}{c}\boldsymbol{R}_{\text {w750 }} \\
{[\%]}\end{array}$ & $\begin{array}{c}\mathbf{C T E}, \mathbf{5 0}^{\mathbf{0}-250}{ }^{\circ} \mathbf{C} \\
{\left[\cdot \mathbf{1 0}^{-6} / \mathbf{K}\right]}\end{array}$ \\
\hline PI-1 & 337 & 526 & 58.1 & 50.0 \\
\hline PI-2 & 284 & 537 & 58.7 & 62.0 \\
\hline PI-3 & 258 & 551 & 59.0 & $122.9^{\mathrm{b}}$ \\
\hline PI-4 & 379 & 543 & 69.0 & 16.8 \\
\hline PI-5 & 344 & 567 & 68.5 & 34.6 \\
\hline
\end{tabular}

${ }^{\mathrm{a}} T_{\mathrm{g}}$ : glass-transition temperatures; $T_{5 \%}: 5 \%$ weight loss temperatures; $R_{\mathrm{w} 750}$ : residual weight ratio at $750{ }^{\circ} \mathrm{C}$ in nitrogen; CTE: linear coefficient of thermal expansion.

${ }^{b}$ Data from $50-200{ }^{\circ} \mathrm{C}$.

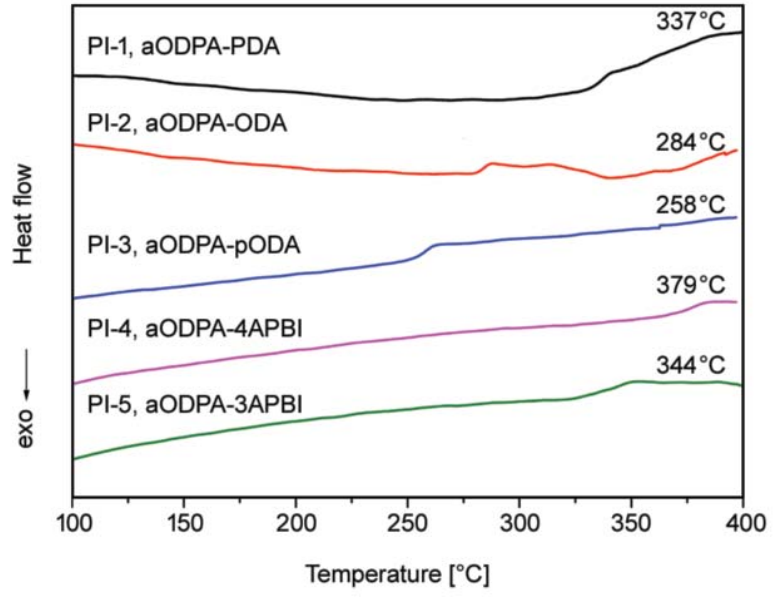

Figure 4. DSC curves for aODPA-PI films

in the rigidity and energy of internal rotation of the polymer chains due to the presence of flexible ether units, which reducing their $T_{\mathrm{g}}$ values below $300^{\circ} \mathrm{C}$, as seen from Figure 4. However, as anticipated, PI1, PI-4 and PI-5 with much more rigid molecular structures exhibited higher $T_{\mathrm{g}}$ values over $330^{\circ} \mathrm{C}$. These results revealed that the effects by introducing highly rigid groups in PIs are effective to increasing their $T_{\mathrm{g}}$ values.

Figure 5 shows the typical dynamical mechanical analysis (DMA) curves for the PI films. The polymers retained their mechanical properties up to about $250^{\circ} \mathrm{C}$ for PI-2, $325^{\circ} \mathrm{C}$ for PI- 1 , and $375^{\circ} \mathrm{C}$ for PI-4. The storage modulus of the polymers dropped dramatically at the temperatures around their $T_{\mathrm{g}}$ and the dropped amplitudes are above $10^{3} \mathrm{MPa} /{ }^{\circ} \mathrm{C}$, showing good thermoplasticity. The good thermoplasticity for the current PIs guarantees adequate interdiffusion of molecular chains in heat sealing procedures for PI and copper foil. This favorable property undoubtedly originates from the high free-volume and weak chaininteraction caused by the distorted structure in aODPA.

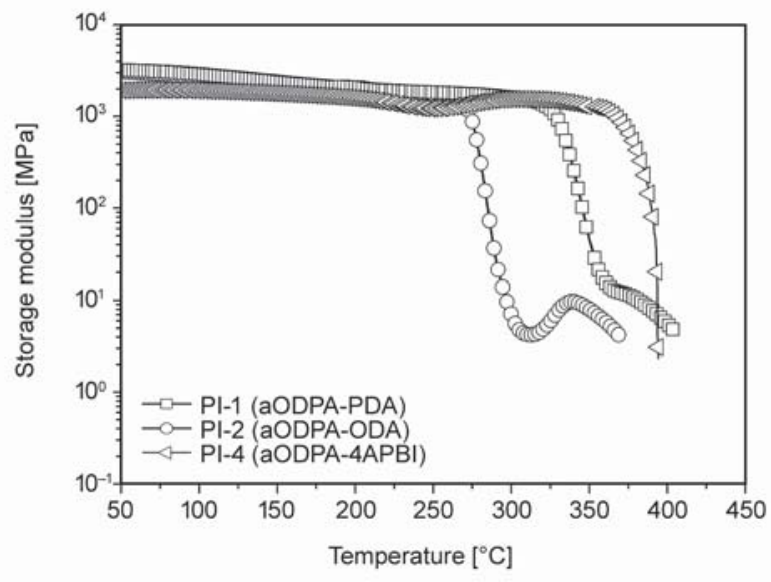

Figure 5. DMA curves for aODPA-PI films 


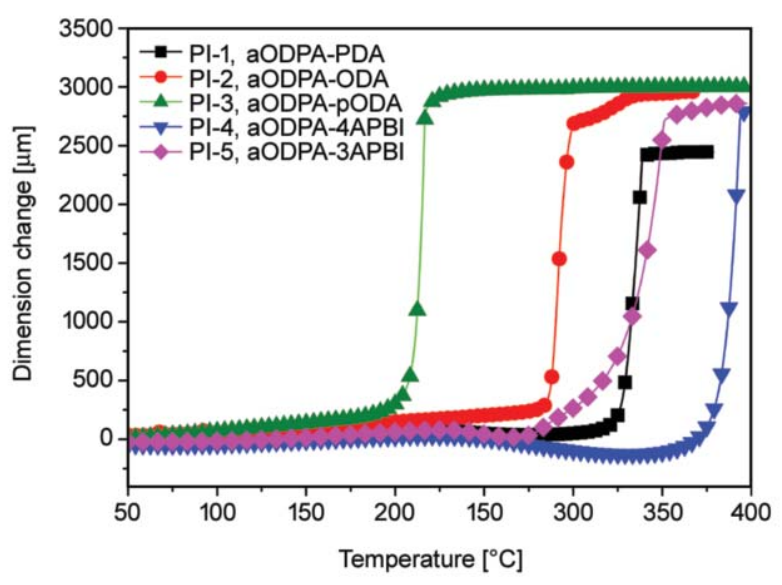

Figure 6. TMA curves for aODPA-PI films

Another important purpose in the current work is to achieve a comparable CTE value for the PI films to be match with the copper foil. One of the most important properties required for the polymer film matrix in FCCL applications is to suppress curling of the components. It has been well established in the literature that curling of the $\mathrm{PI} / \mathrm{Cu}$ laminates is mainly caused by thermal stress arising during the hot pressing procedure in FCCL fabrications. The thermal stress could be effectively weakened by lowering the CTE mismatch between the PI film matrix and copper foil (CTE: $\left.17 \cdot 10^{-6} 1 / \mathrm{K}\right)$. The CTE values of the current aODPA-PIs were evaluated by thermal mechanical analysis (TMA) measurements and the results are shown in Figure 6. As shown in the TMA curves, the PI films exhibited drastic creep around their $T_{\mathrm{g}} \mathrm{s}$, with the CTE values in the range of 16.8 $62.0 \cdot 10^{-6} 1 / \mathrm{K}$ except PI-3. Interestingly, PI-3 exhibited an unexpected low dimensional stability at elevated temperatures. The film obviously expanded when the temperature was higher than $200^{\circ} \mathrm{C}$, although the DSC measurement revealed a $T_{\mathrm{g}}$ of $258^{\circ} \mathrm{C}$. PI-2 exhibited a second high CTE value of $62.0 \cdot 10^{-6} 1 / \mathrm{K}$ in the range of $50-250^{\circ} \mathrm{C}$. PI-4 film displayed a low CTE of $16.8 \cdot 10^{-6} 1 / \mathrm{K}$, which is quite comparable or slightly lower than that of copper foil. The analogue PI-5 with meta-substituted amino structure in the diamine moiety exhibited a CTE value twice higher than that of PI-4.

\subsection{FCCL preparation and evaluation}

PI-1, PI-4, and PI-5 films were chosen to be hot pressed with copper foil, respectively, with the conditions shown in Table 4. Generally, the heat sealing parameters, including heat sealing temperatures, pressure, and time were determined by the $T_{\mathrm{g}}$ values and
Table 4. Heat-sealing properties of aODPA-PI filmsa

\begin{tabular}{|c|c|c|c|c|c|}
\hline PI & $\begin{array}{c}\boldsymbol{T}_{\text {hs }} \\
{\left[{ }^{\circ} \mathbf{C}\right]}\end{array}$ & $\begin{array}{c}\boldsymbol{P}_{\text {hs }} \\
{[\mathbf{M P a}]}\end{array}$ & $\begin{array}{c}\boldsymbol{t}_{\text {hs }} \\
{[\mathbf{s}]}\end{array}$ & $\begin{array}{c}\boldsymbol{d} \\
{[\boldsymbol{\mu m}]}\end{array}$ & $\begin{array}{c}\boldsymbol{P}_{\mathbf{s}} \\
{[\mathbf{N} / \mathbf{m m}]}\end{array}$ \\
\hline PI-1 & 360 & 1 & 60 & 25 & 0.14 \\
\hline PI-2 & 350 & 1 & 60 & 25 & 0.43 \\
\hline PI-3 & 320 & 1 & 60 & 25 & 0.44 \\
\hline PI-4 & 395 & 1 & 60 & 25 & 1.23 \\
\hline PI-5 & 380 & 1 & 60 & 25 & 1.16 \\
\hline
\end{tabular}

$T_{\mathrm{hs}}$ : heat-sealing temperature; $P_{\mathrm{hs}}$ : heat-sealing pressure; $t_{\mathrm{hs}}$ : heat-sealing time; $d$ : heat-sealing film thickness; $P_{\mathrm{s}}$ : peeling strength for PI/Copper composite films

modulus change behaviors for the PI films at elevated temperatures in DMA measurements. The optimal conditions were obtained by observing the micro-interface between the PI film and copper foil, in which homogeneous adhesion was achieved. First, the peeling strength samples were prepared according to the procedures reported before in our laboratory, as shown in Figure 7 [18]. The $180^{\circ}$ peeling strength of the PI/Cu composite films were tabulated in Table 4. PI-4 and PI-5 containing benzimidazole moiety exhibited the highest adhesion to copper foil with the peeling strength higher than $1.0 \mathrm{~N} / \mathrm{mm}$. Actually, it has been known that incorporation of primary or secondary amine groups, which can interact with copper, into PIs could enhance their adhesion [20]. This result is in good agreement with the literature data. The appearance of the PI/Cu FCCL is shown in Figure 8 . It can be seen that, when PI-4 was chosen as the matrix, almost no curling was observed for the FCCL. In the case of PI-5, slight curling was observed at the edge of the FCCL. However, for PI-1, the laminate strongly curled up to a cylinder shape. Apparently, the purpose of the molecular design in the current work is successfully achieved by PI-4.

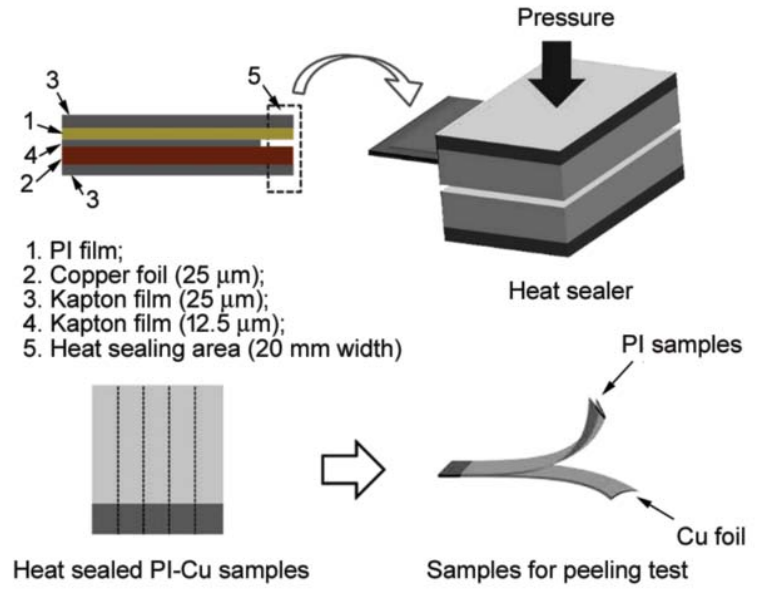

Figure 7. Illustration of heat-sealing process for PI film and copper foil 


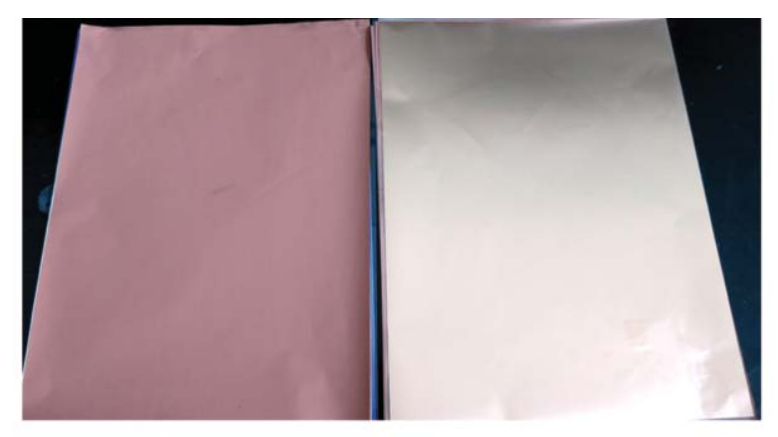

Cu foil

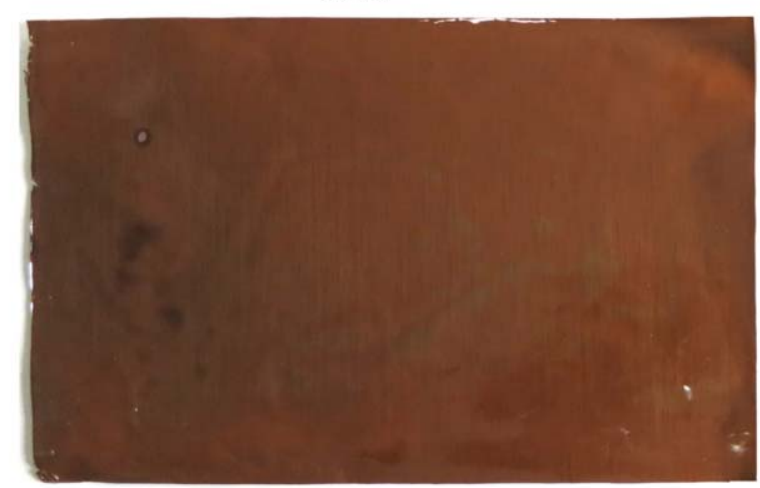

$\mathrm{PI}-4 / \mathrm{Cu}$

Figure 8. Appearance of PI/Cu FCCL

\section{Conclusions}

In summary, a benzimidazole-containing thermoplastic PI (PI-4) was successfully developed from aODPA and 4APBI in order to achieve good comprehensive properties for FCCL applications, including high $T_{\mathrm{g}}$, low CTE, and good adhesion to copper matrix. The current APBI-containing PI-4 exhibited lower CTE value as compared with its soluble analogue reported in the literature, such as those derived from 4APBI, 2,2'-bis(trifluoromethyl)-4,4'-diaminobiphenyl (TFDB), and 3,3',4,4'-benzophenone tetracarboxylic dianhydride (BTDA) (CTE:29.6$55.3 \mathrm{ppm} /{ }^{\circ} \mathrm{C}$ ) [20]. The main defect for PI-4 is its high sealing temperature, which might deteriorate the properties of the copper foil. In our next work, the formulations for PI-4 will be optimized so as to decrease its heat-sealing temperature. Copolymerization with $3 \mathrm{APBI}$ might be an effective procedure for achieving this purpose.

\section{Acknowledgements}

Financial support from the Fundamental Research Funds of China University of Geosciences is gratefully acknowledged.
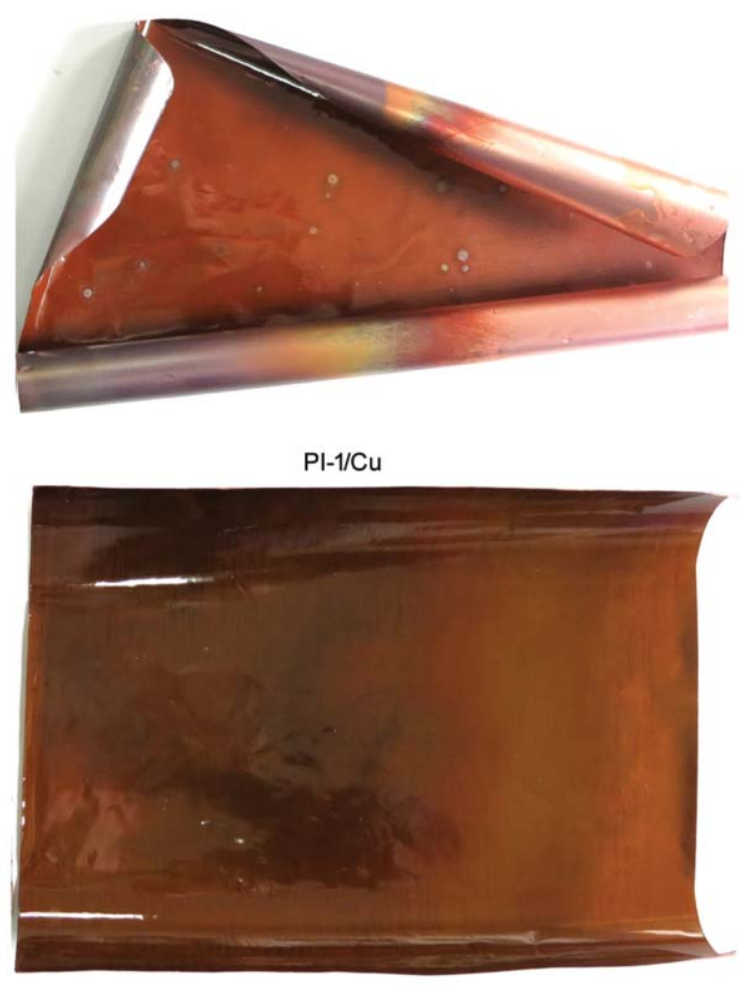

$\mathrm{PI}-5 / \mathrm{Cu}$

\section{References}

[1] Liaw D-J., Wang K-L., Huang Y-C., Lee K-R., Lai J-Y., Ha S-K.: Advanced polyimide materials: Syntheses, physical properties and applications. Progress in Polymer Science, 37, 907-974 (2012).

https://doi.org/10.1016/j.progpolymsci.2012.02.005

[2] Maier G.: Low dielectric constant polymers for microelectronics. Progress in Polymer Science, 26, 3-65 (2001).

https://doi.org/10.1016/S0079-6700(00)00043-5

[3] Ni H-J., Liu J-G., Wang Z-H., Yang S-Y.: A review on colorless and optically transparent polyimide films: Chemistry, process and engineering applications. Journal of Industrial and Engineering Chemistry, 28, 16-27 (2015).

https://doi.org/10.1016/j.jiec.2015.03.013

[4] Volksen W., Miller R-D., Dubois G.: Low dielectric constant materials. Chemical Reviews, 110, 56-110 (2010). https://doi.org/10.1021/cr9002819

[5] Zhao G-F., Ishizaka T., Kasai H., Hasegawa M., Furukawa T., Nakanishi H., Oikawa H.: Ultralow-dielectric-constant films prepared from hollow polyimide nanoparticles possessing controllable core sizes. Chemistry of Materials, 21, 419-424 (2009).

https://doi.org/10.1021/cm802989u

[6] Tsai C-L., Yen H-J., Liou G-S.: Highly transparent polyimide hybrids for optoelectronic applications. Reactive and Functional Polymers, 108, 2-30 (2016). https://doi.org/10.1016/j.reactfunctpolym.2016.04.021 
[7] Hasegawa M., Kaneki T., Tsukui M., Okubo N., Ishii J.: High-temperature polymers overcoming the trade-off between excellent thermoplasticity and low thermal expansion properties. Polymer, 99, 292-306 (2016). https://doi.org/10.1016/j.polymer.2016.07.010

[8] Bag A., Choi S-H.: Microcrack propagation in Cu metal films on a flexible PI substrate during cyclic-bend testing. Materials Characterization, 129, 186-194 (2017). https://doi.org/10.1016/j.matchar.2017.04.022

[9] Kohl P-A.: Low-dielectric constant insulators for future integrated circuits and packages. Annual Review of Chemical and Biomolecular Engineering, 2, 379-401 (2011).

https://doi.org/10.1146/annurev-chembioeng-061010-114137

[10] You J. B., Kim S. Y., Park Y. J., Ko Y. G., Im S. G.: A vapor-phase deposited polymer film to improve the adhesion of electroless-deposited copper layer onto various kinds of substrates. Langmuir, 30, 916-921 (2014). https://doi.org/10.1021/la404251h

[11] Hasegawa M., Sakamoto Y., Tanaka Y., Kobayashi Y.: Poly(ester imide)s possessing low coefficients of thermal expansion (CTE) and low water absorption (III). Use of bis(4-aminophenyl)terephthalate and effect of substituents. European Polymer Journal, 46, 1510-1524 (2010). https://doi.org/10.1016/j.eurpolymj.2010.04.014

[12] Noh B-I., Yoon J-W., Jung S-B.: Effect of laminating parameters on the adhesion property of flexible copper clad laminate with adhesive layer. International Journal of Adhesion and Adhesives, 30, 30-35 (2010). https://doi.org/10.1016/j.ijadhadh.2009.07.001

[13] Kim H. J., Park Y. J., Choi J-H., Han H. S., Hong Y. T.: Surface modification of polyimide film by coupling reaction for copper metallization. Journal of Industrial and Engineering Chemistry, 15, 23-30 (2009). https://doi.org/10.1016/j.jiec.2008.08.016
[14] Ni H-J., Liu J-G., Yang S-Y.: Preparation and characterization of inherently heat-sealable polyimides with high glass transition temperatures. Journal of Applied Polymer Sciences, 133, 43058/14-43058/9 (2016). https://doi.org/10.1002/app.43058

[15] Yokota R., Miyauchi M.: Development of heat sealable polyimide thin films with high space environmental stability for solar sail IKAROS Membrane. in 'Protection of materials and structures from the space environment' (eds.: Kleiman J., Tagawa M., Kimoto Y.) 303-315 (2009). https://doi.org/10.1007/978-3-642-30229-9 28

[16] Yamashina N., Isobe T., Ando S.: Low thermal expansion composites prepared from polyimide and $\mathrm{ZrW}_{2} \mathrm{O}_{8}$ particles with negative thermal expansion. Journal of Photopolymer Science and Technology, 25, 385-388 (2012).

https://doi.org/10.2494/photopolymer.25.385

[17] Fukukawa K-I., Okazaki M., Sakata Y., Urakami T., Yamashita W., Tamai S.: Rational approach for improving optical and mechanical properties of transparent polyimide for FPC substrate. Journal of Photopolymer Science and Technology, 24, 255-258 (2011).

https://doi.org/10.2494/photopolymer.24.255

[18] Ni H-J., Zhang X-M., Liu J-G., Yang S-Y.: Intrinsically heat-sealable polyimide films derived from 2,3,3',4'oxydiphthalic anhydride and aromatic diamines with various ether linkages. High Performance Polymers, 29, 362-371 (2017).

https://doi.org/10.1177/0954008316645170

[19] Morikawa A., Nabeshima S., Satoh A., Moriyama Y.: Synthesis and characterization of polyimide from 4, $4^{\prime}$ diamino diphenyl ether having substituents at 2,2'-position. Journal of Photopolymer Science and Technology, 26, 367-372 (2013). https://doi.org/10.2494/photopolymer.26.367

[20] Chung I. S., Park C. E., Ree M., Kim S. Y.: Soluble polyimides containing benzimidazole rings for interlevel dielectrics. Chemistry of Materials, 13, 2801-2806 (2001)

https://doi.org/10.1021/cm0008381 